\section{Genitourinary Medicine}

Edited by Dr Pat Munday MBChB FRCOG FRCP MD

Consultant Physicians in Genitourinary Medicine, Watford General

Hospital, Watford

\section{Sexual behaviour in Britain: why sexually}

\section{transmitted infections are common}

Kevin A Fenton MBBS DipGUM MFPHM, HIV/STI Division, Health Protection Agency Communicable Disease Surveillance Centre, London; Department of STDs, Royal Free and University College London Medical School

\section{Gwenda Hughes PhD, HIV/STI Division,} Health Protection Agency Communicable Disease Surveillance Centre, London

\section{Clin Med 2003;3:199-202}

Sexually transmitted infections (STIs) cause considerable reproductive morbidity and poor health outcomes, including pelvic inflammatory disease, infertility, ectopic pregnancy, cervical cancer, neonatal disorders and death. ${ }^{1}$ They are often associated with significant social stigma and are a source of psychological stress, with adverse impacts on individuals and their relationships. Early as targeted prevention efforts, can significantly reduce the likelihood of these complications.

Population patterns of sexual behaviour are major determinants of STI and HIV transmission. In Britain, the past decade has seen substantial changes in the epidemiology of these infections.

\section{Recent epidemiology of sexually transmitted infections}

In England, Wales and Northern Ireland, routine analysis of data collected from diagnosis and treatment of STIs, as well over 200 genitourinary medicine (GUM) clinics is used to monitor trends in diagnosed STIs. ${ }^{2}$ Diagnoses of STIs had fallen sharply in the mid- to late 1980s in the wake of the HIV and AIDS epidemic and had remained at low levels until the mid-1990s. However, between 1996 and 2001 diagnoses of acute bacterial STIs have increased substantially:

- chlamydia by $108 \%$

$(34,136$ to 71,055 cases) (Fig 1$)$

- gonorrhoea by $87 \%$

(12,140 to 22,685 cases) (Fig 2), and

- infectious syphilis by $487 \%$

(122 to 716).

These increases are probably associated with a rise in high-risk sexual behaviours, although more testing for chlamydia has also contributed.
STIs diagnosed in GUM clinics represent only the tip of the iceberg as many of these infections are asymptomatic. Chlamydial and gonococcal infections in women usually show no symptoms, and often go undiagnosed. In a populationbased prevalence survey of genital chlamydial infection in Britain, investigators in the National Survey of Sexual Attitudes and Lifestyles (NATSAL) found Chlamydia trachomatis in 2.2\% (95\% confidence interval (CI) 1.5-3.2) of men and $1.5 \%$ (95\% CI 1.11-2.14) of women, with age-specific prevalence highest among men aged 25-34 (3.1\%) and women aged $18-24$ years $(3.0 \%){ }^{3} \mathrm{~A}$ chlamydia screening pilot study in England (Portsmouth and Wirral) tested all sexually active young women attending a range of healthcare settings, including general practice and family planning clinics, regardless of whether they had symptoms. Approximately 50\% of the eligible population aged under 25 years in those areas were tested between September 1999 and August 2000. ${ }^{4}$ Chlamydial infection was found in $10-11 \%$ of women aged under 25 attending healthcare services.

In both studies, many individuals may have been unaware of their infection and therefore could have been at risk of developing chlamydial complications. The higher prevalence in the chlamydia pilot evaluation may reflect differences in the age groups screened, as well as in the behavioural risk profiles of the study populations.

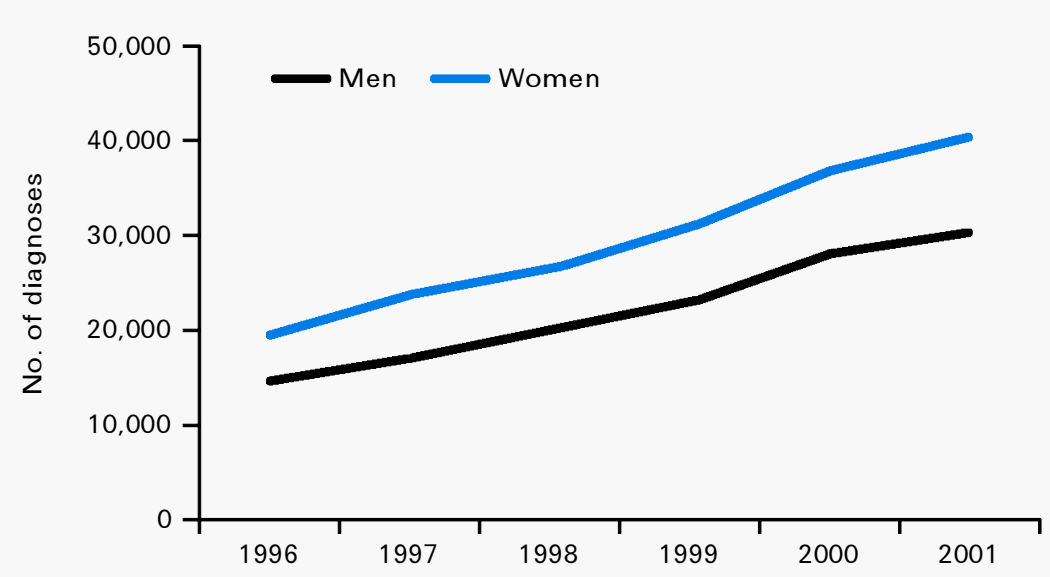

Fig 1. Diagnoses of uncomplicated genital chlamydial infection in genitourinary medicine clinics in England, Wales and Northern Ireland, 1996-2001. 


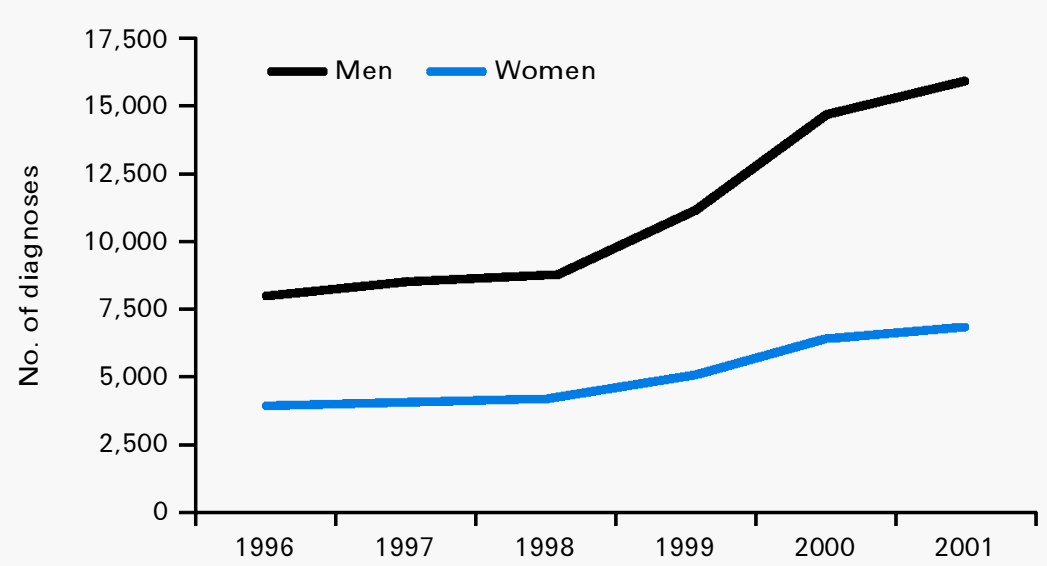

Fig 2. Diagnoses of uncomplicated gonorrhoeal infection in genitourinary medicine clinics in England, Wales and Northern Ireland, 1996-2001.

Certain groups in the population tend to be at particular risk of infection and reinfection with STIs. These include young people, particularly teenage females, gay men and black ethnic minorities.

\section{Young people, particularly teenage girls}

The highest rates of gonorrhoea and chlamydia occur among teenage girls: ${ }^{2} 46 \%$ of the 6,785 females diagnosed with gonorrhoea in 2001 were under 20 years old. Almost a quarter of the 12-15 year old girls diagnosed with gonorrhoea will return with another

\section{Gay men}

There have been several large outbreaks of syphilis in England over the last few years, notably in Manchester, Brighton, ${ }^{6}$ and most recently in London where over 290 cases were diagnosed in the last year. These outbreaks have predominantly involved gay men, many of whom were also infected with HIV. ${ }^{7}$ Gonorrhoea diagnoses among gay men have also episode of gonorrhoea within a year. ${ }^{5}$ more than doubled since 1996 and there is good evidence that HIV transmission in gay men continues at appreciable levels. ${ }^{8}$

\section{Black ethnic minorities}

Several studies have shown particularly high rates of bacterial STIs, especially gonorrhoea, among the black Caribbean population. In London, gonorrhoea rates are thought to be 10 times higher in black ethnic groups than in whites. ${ }^{9} \mathrm{~A}$ quarter of black Caribbeans diagnosed with an acute STI will be diagnosed with another acute STI within a year. ${ }^{10}$

\section{Sexual behaviour: the main driving factor}

\section{Number of lifetime partners}

The most recent data on sexual behaviour in Britain are derived from the second NATSAL in 2000. ${ }^{11,12}$ This study showed substantial changes in social norms and sexual behaviour over the past decade. For both men and women, the number of lifetime heterosexual partners increased substantially between 1990 and 2000 (Fig 3). ${ }^{11}$ The mean number has increased from 8.6 to 12.7 in men, and from 3.7 to 6.5 in women.

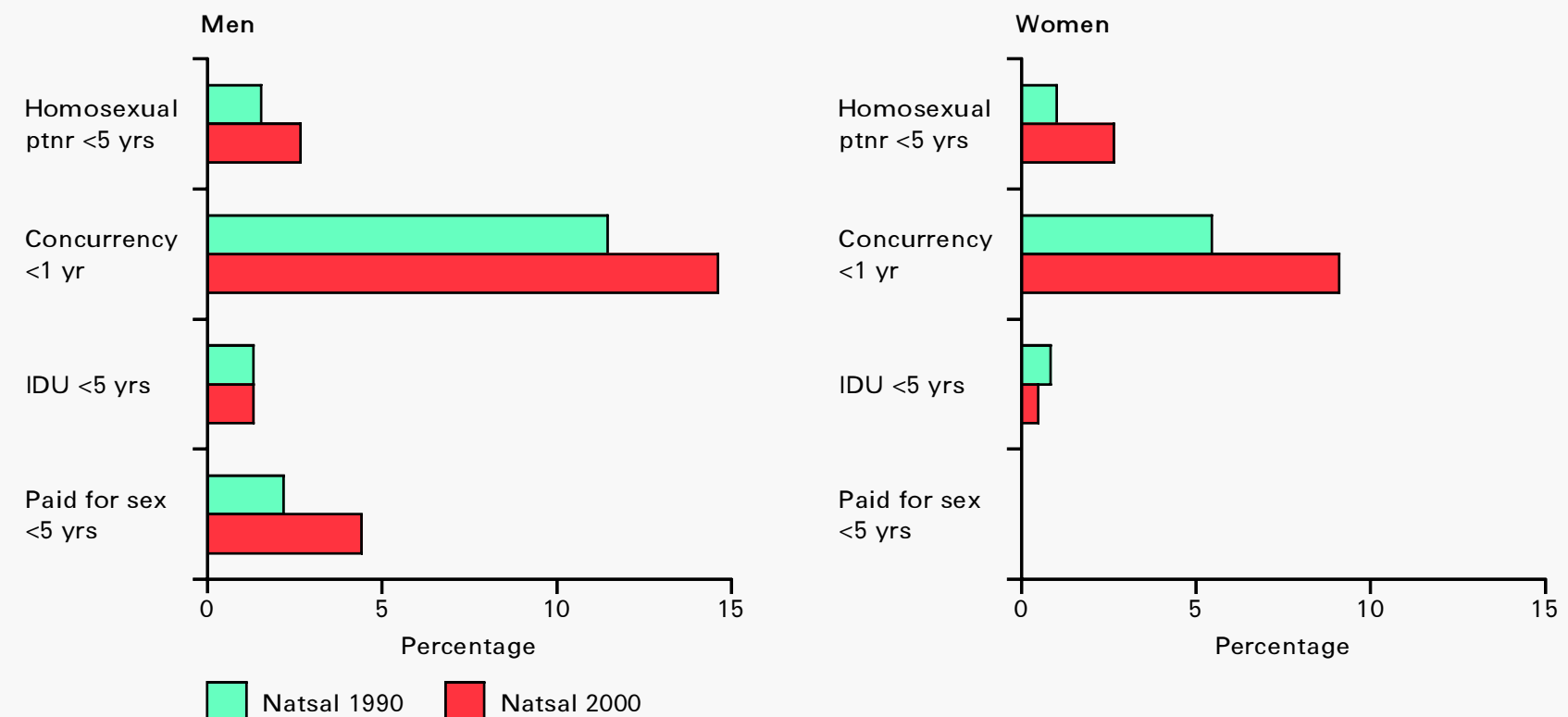

Fig 3. Changes in sexual and drug injecting behaviours over time. Comparison between National Survey of Sexual Attitudes and Lifestyles (NATSAL) 1990 and 2000 (IDU = injecting drug user). 
Although condom use increased over the same period, the greater numbers of sexual partners may have discounted some of the public health benefit. Overall, the percentage of the population who reported two or more partners in the past year and did not use condoms rose from $13.6 \%$ to $15.4 \%$ of men and from $7.1 \%$ to $10.1 \%$ of women between 1990 and $2000 .^{11}$

\section{Concurrent partnerships}

Concurrent partnerships (ie having more than one partnership at the same time) are important for STI transmission dynamics as they increase the probability that an infection will be passed on to more than one person. ${ }^{13}$ Concurrency has become more common since 1990: $14.6 \%$ of men and $9.0 \%$ of women reported such partnerships in 2000. The rate was highest in young people: over $20 \%$ of men and $15 \%$ of women aged 15-24 had a concurrent partnership during the last year. ${ }^{11}$

\section{Age at first intercourse}

The age at first sexual intercourse has been declining steadily over recent generations, with a median age of 16 for men and women born in the early to mid-1980s. ${ }^{12}$ Young people do not always have the negotiation skills to ensure the consistent and effective use of condoms, but as a group, with both higher rates of partner change and more concurrent sexual partnerships, they are already at disproportionate risk of acquiring STIs.

\section{Homosexual behaviour}

Homosexual behaviour has also become more common in Britain over the past decade. Over $5 \%$ of men reported ever having had a homosexual partner in 2000 compared with $3.6 \%$ in $1990 .{ }^{11}$ The percentage reporting a homosexual partner in the last five years also rose. Community surveys of men who have sex with men have seen increases in high-risk sex since 1996. The proportion of gay men in London reporting unprotected anal intercourse with both regular and casual partners in the past year rose from $32 \%$ in 1996 to $44 \%$ in $2000 .^{14}$ Recent growth in traditional (eg saunas and cruising grounds) and new (eg websites and internet chat rooms) venues for meeting prospective sexual partners has substantially increased the opportunities for men who have sex with men to acquire new sexual partners.

Cultural background has a powerful influence on sexual behaviour and attitudes, which may partly explain variations in STI distribution across ethnic groups. However, the relationships between sexual behaviour, ethnicity and STI incidence remain poorly understood and require further exploration.

\section{Other driving factors}

Although sexual behaviour is a key determinant of STI transmission, other factors may be driving the observed increase in STI diagnoses, including:

- high levels of asymptomatic infection

- ineffective partner notification measures, and

- poor access to GUM clinic services. $^{15}$

Consequently, the development of preventive measures should always consider not only the behavioural context but also the provision and utilisation of sexual health services. For some STIs, for example genital chlamydia, improvements in the sensitivity of diagnostic tests and the increasing promotion of asymptomatic testing may also contribute to the growing number of diagnosed infections.

\section{Implications for sexual health and the provision of services}

In concert, the surveillance and research data confirm that STIs are becoming more common and that changes in the patterns and distribution of high-risk sexual behaviours are driving these increases. In addition to the poor health outcomes associated with some untreated STIs, high-risk sexual behaviour also places individuals at risk of infection with HIV. Despite recent therapeutic advances, HIV remains a chronic disease with considerable mortality. More STI diagnoses reflect increasing GUM clinic throughput as well as rising disease prevalence in the community. Many clinics are already operating under severe pressure, ${ }^{16}$ so the effectiveness of GUM clinic-based prevention interventions such as partner notification and behavioural counselling is likely to suffer.

Inequalities in GUM service provision are exacerbated in poor urban areas where high disease prevalence, increasing demand, poor access times and overstretched staff result in a negative feedback loop of service deterioration. The inverse-care law, whereby those in greatest need often have the poorest access to GUM services, is still relevant in Britain today. It is hoped that the development and implementation of the new

\section{Key Points}

Although substantial declines in sexually transmitted infection (STI) incidence were observed throughout the 1980s and early 1990s, new diagnoses of STIs have risen continually since 1996

Distinct 'core groups', such as teenage women, gay and bisexual men and some ethnic minorities, bear a disproportionate burden of disease

Substantial increase in high-risk sexual behaviours seen in the British population over the past decade is probably the main driving force behind the recent rises in STls, although aspects of health service provision and use also play a role

The increasing burden of infection will compound the workload problems already experienced by overstretched genitourinary medicine clinics, such that the quality and effectiveness of clinic-based interventions may suffer

KEY WORDS: sex, sexual behaviour, sexually transmitted infections, transmission 
national sexual health and HIV strategy ${ }^{17}$ will go a long way to raise awareness of STIs and of the need to prioritise their prevention and control.

\section{References}

1 Holmes KK, Sparling PF, Mårdh P-A, Lemon SM et al (eds). Sexually transmitted diseases, 3rd edn. New York: McGraw-Hill, 1999.

2 Public Health Laboratory Service, Department of Health, Social Sciences and Public Safety, Scottish Information and Statistics Division D5 Collaborative group. Sexually transmitted infections in the UK: new episodes seen at genitourinary medicine clinics, 1995 to 2000. London: PHLS, 2001.

3 Fenton KA, Korovessis C, Johnson AM, McCadden A et al. Sexual behaviour in Britain: reported sexually transmitted infections and prevalent genital Chlamydia trachomatis infection. Lancet 2001;358: 1851-4.

4 Department of Health. A pilot study of opportunistic screening for genital Chlamydia trachomatis infection in England 1999-2000: summary report. London: DH, 2002:1-12.

5 Hughes G, Nichols T, Rogers P, Kinghorm G et al. Re-infection with gonorrhoea. Analysis of risk factors from a retrospective cohort study. 80th Spring Meeting of the Medical Society for the Study of Venereal Diseases in association with the Scandinavian Society of Genito-Urinary Medicine. Oslo, 15-18 May 2002.

6 Doherty L, Fenton KA, Jones J, Paine TC et al. Syphilis: old problem, new strategy. Review. BMJ 2002;325:153-6.

7 Fenton KA. Sexual health and HIV positive individuals: emerging lessons from the recent outbreaks of infectious syphilis in England. Review. Commun Dis Public Health 2002;5:4-6.

8 Murphy G, Parry JV, Gupta SB, Graham et al. Test of HIV incidence shows continuing HIV transmission in homosexual/ bisexual men in England and Wales. Commun Dis Public Health 2001;4:33-7.

9 Low N, Daker-White G, Barlow D, Pozniak A. Gonorrhoea in inner London: results of a cross sectional study. BMJ 1997;314: 1719-23.

10 Hughes G, Andrews N, Catchpole M, Goldman $\mathrm{M}$ et al. Investigation of the increased incidence of gonorrhoea diagnosed in genitourinary medicine clinics in England, 1994-6. Sex Transm Infect 2000;76: 18-24.

11 Johnson AM, Mercer CH, Erens B, Copas AJ et al. Sexual behaviour in Britain: partnerships, practices, and HIV risk behaviours. Lancet 2001;358:1835-42.

12 Wellings K, Nanchahal K, Macdowall W, McManus $\mathrm{S}$ et al. Sexual behaviour in
Britain: early heterosexual experience. Lancet 2001;358:1843-50.

13 Rothenberg R, Potterat J, Gisselquist D. Concurrency and sexual transmission. AIDS 2002;16:678-9.

14 Dodds JP, Nardone A, Mercey DE, Johnson AM. Increase in high risk sexual behaviour among homosexual men, London 1996-8: cross sectional, questionnaire study. BMJ 2000;320:1510-1.

15 Hook EW 3rd, Richey CM, Leone P, Bolan G et al. Delayed presentation to clinics for sexually transmitted diseases by symptomatic patients. A potential contributor to continuing STD morbidity. Sex Transm Dis 1997; 24:443-8.

16 Djuretic T, Catchpole M, Bingham JS, Robinson A et al. Genitourinary medicine services in the United Kingdom are failing to meet current demand. Int J STD AIDS 2001;12:571-2.

17 Department of Health. The national strategy for sexual health and HIV. London: DH, 2001. Available at www.doh.gov.uk/nshs/ bettersexualhealth.pdf 